\title{
Domesticating Anti-Lepric Species in Brasil
}

\section{P. H. Rolfs ani C. Rolfs.}

The domestication of anti-lepric species in Brasil has progressed very favourably and given clata that we believe will be helpful to those who contemplate the propagation of these, and allied species.

The project is one for the horticultural scientist to solve. He has the training and experience, also the necessary e(puipment, land and technical assistants. The medical man cannot afford to absent himself from his patients to direct such field investigations. The chemist has quite a generous problem in the preparation and rectification of remedial products without diverting his attention to the clomestication and propagation of plants. However, without the generous co-operation of the medical man and chemists, this, as a horticultural project, would hav

are engaged in combating leprosy should be especially grateful to Dr. H. I. Cole, of the International Leprosy Center, Rio (le Janciro, for his patient and exhaustive work on the Sapucainha. It was at his kindly urging that this paper has been prepared.

We hope that a sufficient number of illustrative photographs have been presented to make the discussion clear: all of them were taken by the senior author and most of them especially for this article.

This brief paper has been limited to results and clata obtained from the three species-the Sapucainha (Carpotroche brasiliensis, Endl.); the Chaulmoogra (Taraktogenus Kursii, King) and the Gorli (Oncoba cchinata, Olv.).

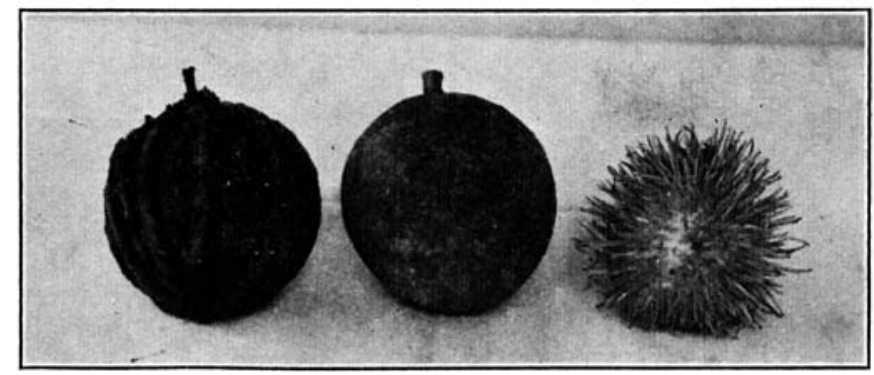

Fla. 1. liruits, medium size, freshly gathered. At left, Sapucainha, hud from E.S.A.V. No. 1. Wt. 270) gms.; No. of seeds, 67; Wt. of seeds, $37 \mathrm{gms}$. Middle, Chaulmoogra, Tree A : 1, l)iameter, 7 cms.; IVt. 290 gms.; No. of sced, 21 ; $\mathrm{Wt}$. of seed, $56 \mathrm{gms}$. liruit mottled with lichens. At right, (iorli, bush ():14. Wt. 70 gms.; No. of seeds, 141; Wit. of seed, $10 \mathrm{gms}$. 


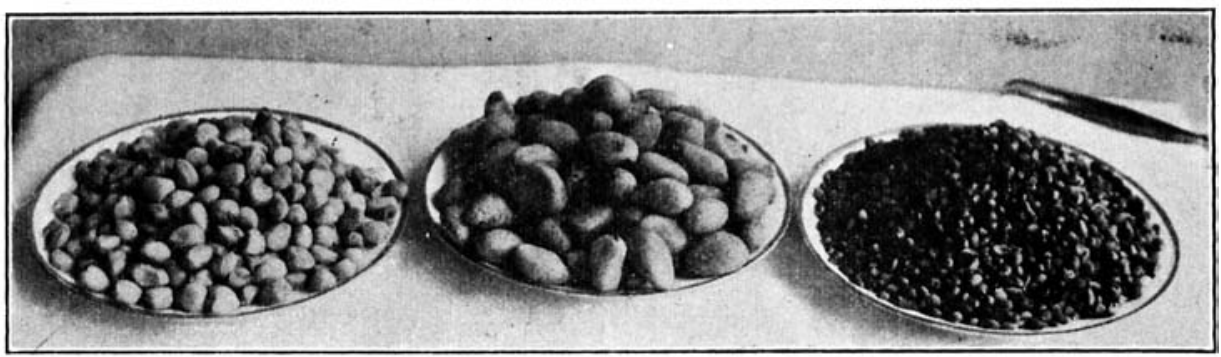

Iisi. 2. Airdried Sced; 1937 (irop. At left, Sapucainla; Wi. 250 gms.; Vol. 540 cc.; No. of seeds, 462. Nidllle, Chaulmoogra, Wt. 250 gms.; Volume, 675 cc.; No. of sceds, 94. At righlı, Gorli, Wt. 250 gms.; Volume 430 cc.; No. of sceds, $3500 \pm$ (40 gms. counted 557.).

\section{TIIE SAPUCAINHA.}

The Sapucainha, Carpotroche spp., is found natively in Brasil from the Fecleral District to the upper reaches of the Amazon and beyond the Brasilian border. Chemical analyses had shown that the family Flacourtiaceæ contained eight species with a varying per cent. of an oil analogous to Chaulmoogra oil. (1) The gienus Carpotroche contained three species: C. brasiliensis, Endl., C. longifolia, Benth. and C. integrifolia, Kuhlm.

The species Carpotroche brasiliensis, Endl., includes many varients : aspect and size of fruit; variation in size of bloom; variation in size of seed; variation in leaves; type of growth of the trees; each so divergent that the extremes might be regarded as different species. Before taking up the problem of clomestication seriously, it was of great importance that we should know definitely that the individual tri

oil content. Fortunately Dr. G. S. Jamieson of the Laboratory of Oils, Waxes and Fats of the United States Department of Agriculture, was interested in the same problem from a chemist's point of view. His generous co-operation greatly facilitated the selection of the parent trees with which to initiate the horticultural investigations. Being monoecious-dioecious (see Fig. 3), the group is constantly subjected to cross breeding. Under native conditions, the trees bearing staminate flow

bearing monoclinous ones. Dr. J. Geraldo Kuhlmann found the proportion to be about sixt.

Ynez Mexia of Berkeley, California, found them more or less ten to one. Our counts in the native habitat gave similar proportion. In our orchards, seedlings from E.S.A.V. Tree

The numbers in parenthesis refer to those in Literature at close. 
No. 1 and E.S.A.V. Tree No. 2, averaged four staminate trees to three monoclinous ones. The great preponderance of staminate trees in the forests may be lue to poachers cutting the bearing trees to gather the fruit.

Field observations suggest that the species is self sterile or is not generally self fecundated. Such a situation is encountered in the avocado. Similarly some varieties of apples need to be cross pollinated to bear an abundant crop.

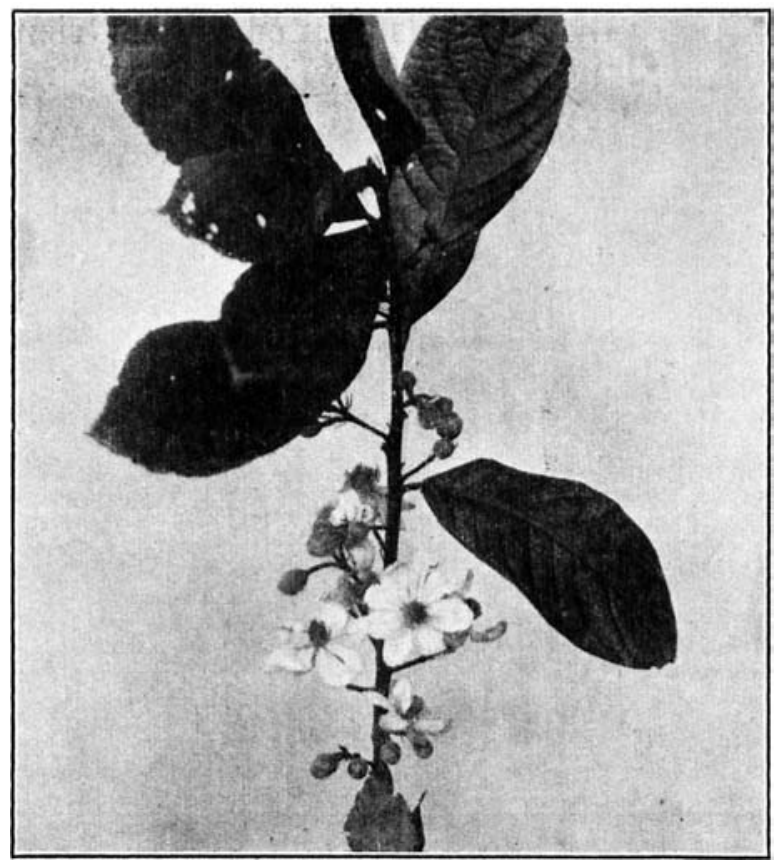

Fig. 3. Sapucainha Flower. Staminate; Tree B:53; 5 cms. diameter; $50 \pm$ stamens; flowers occur in profusion for several weeks. Growth buds visible above fenduncles.

In other words, the presence of pollen bearing stamens in a monoclinous flower is not complete evidence that it is self fertile.

\section{Why Domesticate the Sapucainha?}

The native supply of seed is adequate for the present. Already there is a diminishing return. Seed hunters for the most part are poachers. Fincling a fruiting tre cut it clown to gather the crop). (Very much like the pecan hunters on the lower Mississippi some seventy years ago.) While we were scouting for productive trees, it was necessary for us to gain the confidence of the owner that we would not abuse our.privilege. The following incident illustrates 
the effect of poaching. (On one property, said to contain over three thousand Sapucainha trees, our scout found only sixteen fruiting ones from which he gathered less than sixty kilos of fruit. Yielding about four kilos of seed. Average, 5()() gms. per fruiting tree.

Numerous incidents come to mind where the product from domesticated plants has quite displaced that from the native source. The vast and what was heralded as inexhaustible rubber supply of the Congo and Amazon have been overshadowed by the orchards planted in the Orient. Andean cinchona planted in Java is now the world's reliance for quinine.

The Project. The following is a brief outline of the task before us, for clomesticating the Sapucainha: (1) Locate highly productive trees (see Fig. 5). This required persistence and patience (lots of the latter). (2) Ascertain the oil content of the seed from all of the leading trees. Dr. Jamieson's co-operation was splendidly helpful. (3) Discover some convenient method of a sexual reproduction. The " $\mathrm{T}$ " method (discussed later) did this - a most agreeable surprise. (4) Precocious or not precocious? Productive trees growing spontaneously gave evidence of being decades to a half a century olcl. Results-another agreeable surprise.

\section{Precocity of Cultivatei Trees. (3) and (4).}

In February and March (late summer), 1927, we removed all seedlings more than twenty centimeters tall from the seedbed and planted them directly to an orchard. In November, 1929, Tree B:100. only thirty-three months from the seedbed, matured nine fruits, yielding 532 seeds. A native tree about forty years old and reputed to be very productive, $\mathrm{yi}$

most productive seedling trees in our orchards have fruited so heavily that they would have succumbed to their environment but for cultural attention. Many budded individuals and some of the seedling trees in the College orchards, produced more fruit at five and six years old, than did the entire wild orchard of "three thousand trees" in the forest referred to in another place.

Some of the buds produced bloom the year after being inserted. The second year some fruit were allowed to remain on the most vigorous. The following year some trees were so heavily loaded that the limbs had to be propped to keep them from breaking. 


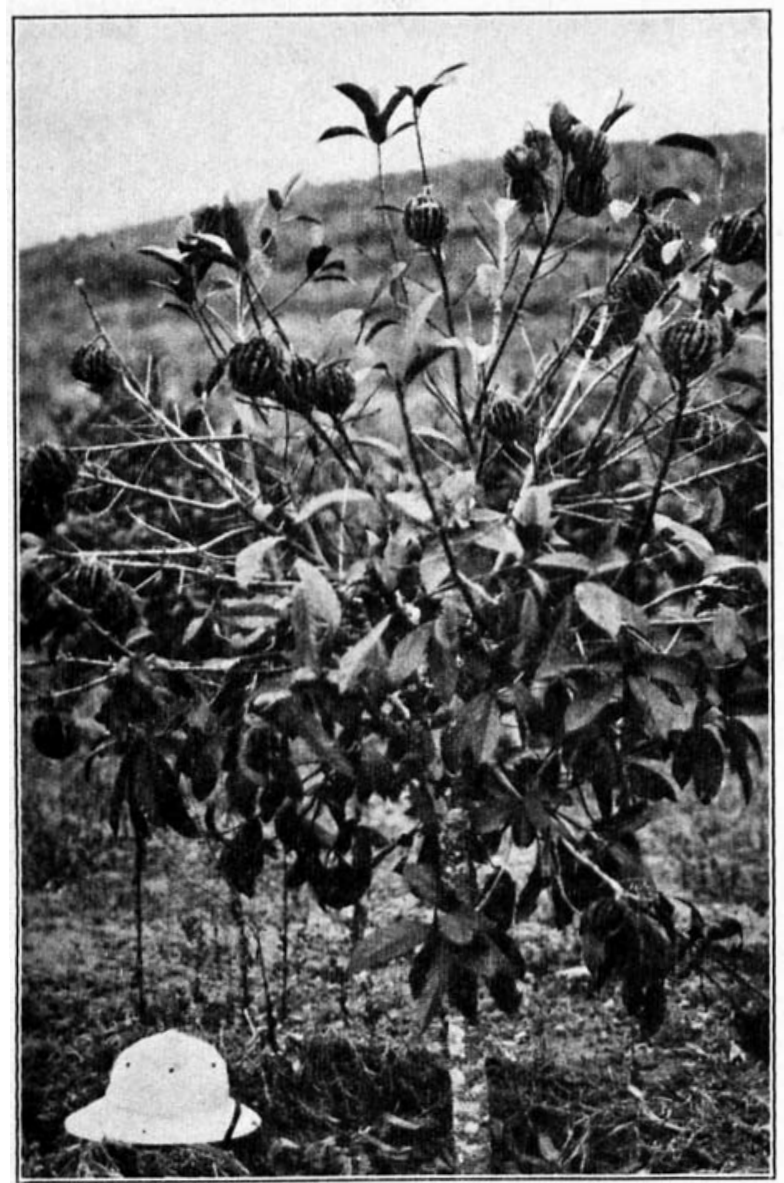

Fili, 4. Budded Orchard Tree. Bud from E.S.A.V. No. 1 inserted on seediling from E..S.A.V. No. 2, by Prof. Cuimaraes I uque; ISud approximately 5 yrs. old. P'roducing two kilos sced. Over cropping caused shedding of leaves. Photo Aug. 9, 1937, near end of dry season. Compare with Fig. 1 and Fig 5.

\section{Propagation.}

In its native element the Sapucainha exists as an unclergrowth in the forests. Occasionally bearing trees are encountered growing near cabins and residences. The oil being employed as a remedy for skin diseases and to destroy vermin attacking man and domestic animals.

In 1924, when the writers undertook this project they were under no illusions that it would be speedily successful. The senior writer, (luring thirty years (1891-1920), had materially aicled in the clomestication of the pecan nut. He was the first to publish on the bucl proplagation of the avocado. (Bul. 104, B.P.I., U.S. Department of Agriculture, 1904.) These experiences were invaluable as guides in 
domesticating the Sapucainha. information on its propagation.
There was no pulblished The verbal teaching was verbose. No matter. Icleas, apparently good, had to be triell. C. IF. Kettering has saicl: "In research you need a lot of intelligent ignorance." The tales that seeds retained their vialbility for more than a year; even years, and that they germinated spontaneously when sown were very interesting; but had one serious (lefect-they were not true. Details of of the many unsuccessful leads would be neither interesting to the writers nor profitable to the reader.

In this brief discussion only an outline of the operations that proved highly successful are presented. The story is simplicity itself; after it has been worked out.

\section{The Nursery.}

Our first attempt at establishing a nursery was by transplanting small trees from the forests. It ended in failure. (Please pardon this inadvertence, we promised to avoid recounting false leads.) This experience made us timid in transplanting either from the seedbed or front the nursery. Later we discovered that the Sapucainha transplants as readily as does citrus under similar conditions; more readily than do avocados.

Incompatibility of stock and scion are often encountered. The investigator must bear this in mind. By using bucls from E.S.A.V. No. 1 and inserting them on seedlings from the same tree we were reasonably certain of an affinity. Not necessarily the most congenial. Later on we discovered that buds from this tree took quite readily on seedlings from E.S.A.V. No. 2, though the two mother trees differ markedly from one another. Future investigators may find another species of Carpotroche or even another genus of the Ilacourtiacece, more desirable as a bud stock. (Certain varieties of citrus do best when inserted on a stock belonging to another genus.)

Seedbed. After ripening of the fruit and before germination of the seed, there is a resting period. During this time the power of germination is easily lost. Our favourite preservative is well rotted, humid bagasse. Moist sphagnum or powdered charcoal are doubtless equally good. Some three months after ripening, the radicle and cotyledons of the seed about to germinate show signs of development. Under commercial conditions, seeds appear to lose their germinating quality readily. In 1926 we acquired some twenty kilos, not a seed of which germinated; it was said to be fresh. After that we used seed from fruits we gathered. 
The Nursery Row. When the seellings are twenty to thirty centimeters tall they may be transplanted to the nursery row. Siet a half to three-(puarters of a meter apart: and rows a meter apart are good distances. L'rovicle a half shade and protect against dry winds until sturdy growth has been made.

Budding. The " $\mathrm{T}$ " method is the simplest and very süccessful. One of our budders had an instance of $90 \%$ take. The bark of the stock should slip perfectly. The stock at the point of insertion should be two to three centimeters in cliameter. The bark chestnut coloured. Being hollow (" canudo de pito," " pipe stem " in popular vernacular), the smaller stocks are unnecessarily troublesome; the stocks whose l)ark has turned grey at point of insertion gave a low percentage of " takes." (The " patch " bucl may prove suitable for such stock.) (Seedlings propagated in pot or basket rarely take a " $\mathrm{T}$ ” bud. They may respond to inarching or to grafting.)

Budding the Sapucainha is easy provided the stock is in optimum condition and one has experienced men to do the budding. Fortunately we had scores of young men trained by having budded thousands of citrus. We chose three of the most proficient for our first test. These were constantly under the eyes of the senior writer and of Humberto Bruno, Professor of Pomology.

Wrap the buds in waxed tape, leave well sealed for a month, if you can restrain yourself that long; examine, and those whose " eyes " have begun to fill, may be unwrapped. Two weeks later examine the resealed buds; som

"lean" for three months or even more and finally "spring."

Cut off the stock a handsbreadth or two above the bud, retain leaves above the bud if convenient. Remove all leaves below the bud.

Bud Sticks fifty centimenters long were cut from E.S.A.V. Tree No. 1, while in dormant condition. Those with grey bark and those of less than a half centimeter diameter were rejected.

\section{( ) RCHARI).}

The site chosen should be such as is employed for a citrus or an avocado orchard. Deep soil: well drained but not droughty. Sapucainha, especially the bearing trees, are sensitive to droughty soil than are citrus or avocados. If a drying out of the soil occurs when the fruit is small, heavy 
casting will occur. If after the seeds have become " meaty," heavy (lefoliation. (S.ee Fig. 4.) Either may be readily obviated by shallow cultivation (dust mulch) or by mulching with vegetal)le matter. (Unfavourable moisture condition of the soil often causes heavy casting of young citrus and avucado fruits.)

If set out in a single row, four to five meters apart will be a good distance. One staminate tree to four monoclinous ones is a good proportion. If set out in a solid block, the ratio may be one to eight: i.e., trees $2,5,8$, etc., in rows 2 , 5 , 8, etc., may be staminate. Staminate trees need to be pruned back to prevent them from dwarfing the fruiting: ones.

Cold. On July 6, 1928, the "Posto Meterologico " on the College grounds recorded four-tenths of a degree below zero (Centigrade). Considerable defoliation followed and slight bark injury near the ground, to a small number of the seedlings. On the older trees, no casting of leaves or bark injury could be detected. The same frost " scorched" the terminals in our citrus nursery. The Sapucainha and lemons appear to be about equally sensitive to cold. (For data on climate at Viçosa, see (haulmoogra.)

\section{Productiveness.}

The E.S.A.V. Tree No. 1 carries the reco d for productiveness. In 1929 it matured 798 fruits (see Fig. 5), weighing 191 kilos; yielding 28 kilos of air-dried seed; the largest fruits weighing slightly over a kilo and the smallest sixty grams. Thus the seed yield was about six per cent. by weight of the mature fruit. The estimated oil eleven and a half kilos. In general the ratio of seed to fruit is higher in the large fruits than in the small ones; also in the spherical fruits than in the oblong and pear-shaped. However, the thickness and weight of shell varies considerably with the different wild trees.

Longevity. In 1926, Cel. Alberto Pacheco of Viçosa, catching our enthusiasm, donated Tree No. 1 to the College. We estimated it to be about fifty years old. Some fifteen or twenty years previously, the tree had been fell

by poachers. Later two of the "sprouts" had been felled. After the tree came into our possession, encroaching forest trees and brush were removed. Being careful to conserve staminate trees growing in the brush, of which there were a score or more, within some 25 meters. No other cultural care was given, 


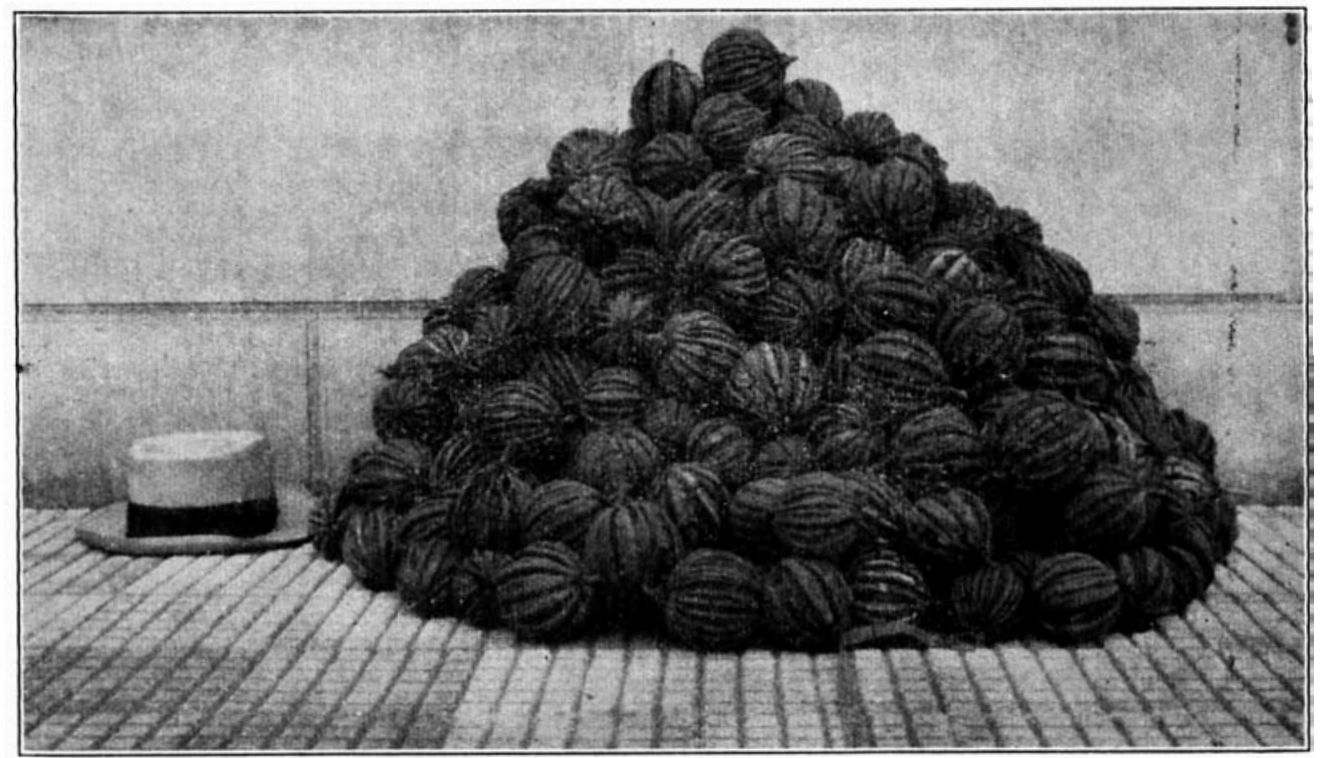

Fic. 5. The 1929 Crop from E.S.A.V. Tree No. 1. Appears to be record crop. Tree about sixty years old; twice cut down; estimated oil content. eleven and a lialf kilos. Largest fruit over $10 \mathrm{cms}$. long; wt. over a kilo. I3udded trees hegan cropping at the years old. Requires 9 to 10 montlis from flowering to (lropling of fruit.

\section{RESUME.}

1. By diligent search and perseverance, productive and otherwise suitable mother trees were discovered.

2. The seedbed is the despair of the amateur.

3. The nursery is the key to success in Sapucainha domestication.

4. The Sapucainha is more precocious than Citrus.

5. Many buds six years old produced two kilos of seed in 1937, in spite of having been stunted by being allowed to over-crop during previous years.

6. ()nly occasional seedlings seven years from the seedbed were equally productive.

7. Longevity is assured; the mother tree of stock and of our buds (E.S.A.V. No. 1) is now some sixty or seventy years old.

\section{CHAULMOOGR A.}

\section{(Taraktogenus KurZII, King.)}

During the International Centennial Exposition at Rio cle Janeiro, in 1922, there was an exhibit of anti-lepric plants. Toward the close of the Exposition our good friend, Dr. Frank Lamson-Scribner, sent us a small shipment of those plants that were still alive. (A Centennial Exposition is not an ideal place for conserving the vitality of tender forest seedllings.) One specimen, labelled Chaulmoogra, S.P.I. No. 52,514 , arrived alive and was planted Jan. 4, 1923. After some six months of industrious attention, it showed manifestations of growth. We called it the Centennial Tree. 
Probably the oldest living Chaulmoogra in South America. Photographs illustrating the vigorous growth of this specimen in 1924 aided us materially in securing additional seedlings. In 1925, during a visit to Washington, Dr. K. A. Ryerson, in charge of Plant Introduction and Distribution, U.S. Department of Agriculture, promised us all the seedlings remaining in the greenhouses.

From Dr. Rock's discussion of the native habitat of the Chaulmoogra in Burma (see Nat. Geo. Magazine, Mar., 1922), we felt certain that in the highlands of Minas Geraes, a congenial location could be discovered. The climate and altitucle of Viçosa seem to correspond closely to that of the native habitat. The altitule is 650 meters. For the ten year period of 1925-34 the extreme variations of temperature were from eight-tenths of a (legree below zero Centigrade to 35 degrees above. The rainfall for the same period averaged one thousand three hundred and seventy millimeters (nearly 55 inches), occurring mainly during the five summer months (November to March). An average of 132 rainy days per year were recorded.

March 29, 1925, we received ninety-three seedlings labelled Chaulmoogra, S.P.I. No. 56,633. They averaged forty centimeters high. Illustrated in " A Lavoura." Nine of the larger were forwarded to Dr. Felisberto Camargo, Director of the National Experiment Station at Deodoro, Federal District. The remaining eighty-four were set out in a nursery to attain robustness and size suitable for planting in an orchard. In April, 1926, some seventy-eight were set out. A half clozen were rejected as being too weak.

\section{The Or(hari).}

November 1, 1937, forty-two of the original eighty-four seedlings were three meters or more tall; nine less than two meters, but looking healthy. Thirty-three, including those rejected in the nursery, had died from other causes than neglect, attacks by insects or visible disease. Thirty-seven of them robust to very vigorous; i.e., over forty per cent.an excellent showing. (In citrus only about twenty-five per cent. of the seedbed seedlings are expected to make acceptable orchard trees. Citrus has been domesticated for hundreds

Staminate Trees. The proportion of staminate trees is uncertain. Owing to the relatively small number of trees in the orchard, the data would not compensate for the labour involved. Unchecked trees would have to be risited almost 
(laily for alout ninety lays. Staminate flowers are ephemeral; opening in the early morning and are likely to be shed the next. There is a great variation in the number of flowers produced. In 1937, Trees I II :4 and A : 17 each produced twenty times as many as dicl Tree IV:3. The latter is the most stately tree in the orchard, pyramidal, six meters tall and six meters of spread, but produced relatively few flowers. (A veritable dressed up (landy; useful only as a show specimen.)

(To be continued.) 